\title{
Bulut Bilişim ve Geleneksel Alternatiflerinin Karşılaştırılması: İşletmeler için Avantajlar, Riskler ve Geçiş Önerileri
}

\author{
Comparison of the Cloud Computing and the Traditional Alternatives: Advantages, \\ Risks and Advices for Migration
}

\author{
Dr. Suat ATAN
}

\begin{abstract}
$\ddot{\mathbf{O} z}$
Web tabanlı bir yazılım uygulamasını barındırmak için uzun bir zaman boyunca kullanılan yegâne araç, sunucu edinme veya kiralama yoluyla web uygulamalarını kullanıcıların hizmetine sunmaktı. Bulut teknolojisinin ortaya çıkışı ile bu yönteme önemli bir alternatif ortaya çıkmıştır. Bulut sayesinde başta yazılım uygulamalarını barındırma hizmetleri olmak üzere, dosya depolama, veri işleme, veri tabanı barındırma gibi birçok hizmet Google ve Amazon gibi büyük şirketlerin yanında irili ufaklı birçok başka şirket tarafından da sunulmaya başlanmıştır. Sunulan hizmetler bulut başlığı altında tek bir hizmetten birden fazla hizmete kadar değişmektedir. Bulut kavramı sunulan servislerin dışsallığına gönderme yapmakla beraber yeterli olanağa sahip şirketlerin kendi bünyelerinde de oluşturabilecekleri bir altyapıyı da ifade etmektedir. Türkçe yazında bulut teknolojilerine yönelik ilgi mevcut olmakla birlikte bu çalışmalar bulut çözümlerinin kavramsal boyutlarını ele almakta ancak işletmeler açısından pratik yararları değerlendirmemektedir. Bu çalışmada, bu boşluğu doldurmak amacıyla yönetim bilişim sistemleri perspektifinde bulut platformunun olumlu ve olumsuz özellikleriyle ilişkili yazını incelenmiş; daha sonra yazında geçen ve risk veya olumsuzluk olarak ele alınan konuların yeni girişimler için geçerli olmayabileceği ortaya konmuştur. Ayrıca işletmelerin özellikle yeni girişimlerin bulut platformunu kullanmalarının yaratacağı faydalar ve geleneksel alternatifleri ile mukayesesi ele alınmıştır.
\end{abstract}

Anahtar Kelimeler: Yönetim bilişim sistemleri, bulut teknolojiler, büyük veri.

Makale Türü: Araştırma

\begin{abstract}
Up to emerging cloud technologies, the only way to host a web application was by purchasing or renting a server or using hosting services. The cloud technology emerged as a new alternative in the market. With cloud technology, many services, such as file hosting, data warehousing, and web hosting have begun to be offered by small and large companies such as Google and Amazon. Services which offered by these companies vary from a single service to multiple services under the cloud technology title. The 'cloud' concept refers to the externalities of the services offered and also refers to the infrastructure that companies with sufficient capabilities can create in their own structures. While there is interest in cloud technologies in Turkish literature, these studies deal with the conceptual dimensions of cloud solutions but do not assess their practical benefits in terms of enterprises. This study examines the positive and negative aspects of the cloud platform in terms of management information systems in order to fill this gap and it is revealed that the topics which considered as risk or negativity may not be valid for new ventures. In addition, the benefits of usage of the cloud technologies and its alternatives for enterprises especially for new ventures have been evaluated.
\end{abstract}

Keywords: Management information systems, cloud technologies, big data

Paper Type: Research

\footnotetext{
${ }^{1}$ Tarım ve Kırsal Kalkınmayı Destekleme Kurumu, yazılım geliştirme uzmanı, suat.atan@tkdk.gov.tr.

Atıf için (to cite): Atan, S. (2020). Bulut bilişim ve geleneksel alternatiflerinin karşılaştırılması: işletmeler için avantajlar, riskler ve geçiş önerileri. Afyon Kocatepe Üniversitesi Sosyal Bilimler Dergisi, 22(3), 747-759.
} 


\section{Giriş}

Literatürde bulut bilişiminin tanımı ile ilgili olarak görüş birliği mevcut değildir (Henkoğlu ve Külcü, 2013:63). Ancak bulut bilişim, sunucu kaynaklarını kullanıcılara müşterek olarak kullandırılan, kullanıcıların ihtiyaç duyduğu miktarda sunucuların kullanımına olanak veren, yönetimi görece kolay bilgi servisleri olarak tanımlanabilir (Elitaş ve Özdemir, 2014:94). Görece yeni bir teknoloji olan bulut bilişim hali hazırda birçok organizasyonun sahip olduğu bilgi işlem altyapısından farklıdır. Bu nedenle öncelikle bulut olmayan bilişim türünü ya da geleneksel yaklaşımı ifade etmek yerinde olacaktır. Yaygın bir şekilde kullanılan ve organizasyonun kendi ihtiyaçlarına göre web, dosya veya e-posta sunucularını kendisinin sağladığı ve bu altyapının bakım ve takibini de kendi yaptığı durumlar geleneksel olarak tanımlanabilecek anlayıştır. Bu anlayışa göre bir organizasyon sahip olduğu yazılımı dış dünyaya açmak için tüm kontrolü ve mülkiyeti kendisinde bulunan bir sunucuya sahip olmalı ve onu yapılandırmalıdır. Bu sunucuların satın alınmasından sonra söz konusu yazılımın erişime açılması için sunucunun gerekli işletim sistemlerinin sunucu sürümlerinin edinilmesi gerekmektedir (Windows IIS, Apache, Tomcat, Glassfish gibi araçların kurulması ve yapılandırılması gerekmektedir). Daha sonra işletme kendi bilgi sistemlerini bu sunucular üzerinden paylaşıma açmaktadır. Söz konusu süreç bununla da sınırlı değildir: Bu sunucuların internete açılması ile saldırı riski ile karşı karşıya kalındığından sunucuların güvenlik önlemlerinin alınması, sunucu yazılımlarında ortaya çıkan güvenlik açıkları ile ilgili güncellemelerin yapılması ve sunucuların fiziksel olarak güvenli koşullarda muhafazası gerekliliği ortaya çıkmaktadır. Organizasyon büyüdükçe bu gereklilikler artmakta, daha fazla sayıda sunucu edinme, bu sunucuların birlikte çalışması için özel farklı yazılımlara sahip olma gerekliliği gibi durumlar ortaya (nginx gibi) çıkmaktadır. Bu aşamadan sonra ise işletme yazılımının geliştirilmesi ile ilgili departmanın yanı sıra bir de sunucuların bakımı ve sürdürülmesi için ek departmana ihtiyaç duyacaktır. Bu amaçla yapılan yatırımlarla ortaya çıkan donanımsal ve insan kaynağı kapasitesi, işletmenin bu kapasiteye ihtiyacının dönemsel dalgalanmaları ve düzensizlikleri nedeniyle bazen çok atıl bazen de kapasitesinin üzerinde bir yüklenmeye maruz kalabilir. Bu durumu optimize etmek işletmeler için kolay olmamaktadır. İşletmeler kendi sunucularını edinmek yerine bu ihtiyaçlarını dışarıdan temine (outsource) yönelerek bu alanda özelleşmiş firmalardan sunucu kiralayabilmektedirler. Kiralama yerine sadece barındırma hizmeti için belirli bir miktardaki alanı tahsis etmek üzere hizmet alma (hosting) da sıkça başvurulan yollardan biridir. Böylece işletme sadece ihtiyaç duyduğu yazılımın geliştirilmesi/edinilmesi için kaynak ayırmakta, bu yazılımın dağıtımı için önemli miktarda kaynak ayırmaya ihtiyaç kalmamaktadır. Sadece barındırma hizmeti ele alındığında, bulut üzerinden barındırma hizmeti de geleneksel yöntemlerden farkı olmayan bir fonksiyon icra etmektedir. Ancak bulut bilişim sözleşmeleri, bir organizasyonun dışarıdan hizmet almak suretiyle eriştiği hizmet alım sözleşmelerinden farklıdır (Vithayathil, 2017). Bulut bilişim sözleşmeleri hizmet alım sözleşmeleri ile benzeşmekte iken, geleneksel sözleşmeler daha ziyade bilişim altyapısının kiralanmasını konu edinmektedir. Bulut olmayan bilişim türlerinin sahip olduğu dezavantajlar düşünüldüğünde bulut bilişim farklı bir alternatif olarak ön plana çıkmaktadır.

$\mathrm{Bu}$ çalışmada bulut bilişim ile geleneksel alternatifleri ilgili yazın 1şığında değerlendirilmektedir. Çalışmanın birinci bölümünde bulut bilişimin kavramsal çerçevesi, ikinci bölümde bulut bilişiminin olumlu yönleri, üçüncü bölümde olumsuz yönleri değerlendirilmiştir. Üçüncü bölümden sonra olumsuz yönlerle ilgili ortaya çıkan tablodaki kavramsal problemler analiz edilerek son bölümde işletmelerin bulut bilişime dayalı olarak bilgi sistemlerinde yapabilecekleri etkinlik arttırıcı öneriler ele alınmıştır.

Bulut bilişimle ilgili bir kavram kargaşası mevcuttur. Oracle CEO'su bulut bilişimle ilgili olarak şunu söylemektedir: "Şu ana kadar yaptığımız her şeyi bulut bilişim olarak yeniden tanımladık. Bulut bilişim ifadesi ile reklamlardaki kelime değişikliği dışında farklı olarak ne yapabileceğimizi anlamadım" (Armbrust vd., 2010:52). Bu durum, bulut bilişim öncesinde geleneksel sıfatı ile tanımladığımız çözümlerin halen birer alternatif olarak var olmaya devam 
ettiğini de ortaya koymaktadır. Gerçekten de bulut bilişimle geleneksel alternatiflerinin de amaçları aynıdır ancak yaklaşım ve uygulamaları ciddi farklılıklar barındırmaktadır.

Bulut bilişim kavramının ortaya çıkışından önce, "grid" biliş̧im adı verilen benzer bir teknolojik yaklaşım mevcuttu. Daha sonra 90'lı yılların ortasında "grid" bilişim kavramı, enerji nakil hatları kelimesinin İngilizcesi olan "power-grid" kavramı üzerinde bu hatların yaygınlı̆̆ı, bağlanılabilirliği ve birlikte çalışabilirliğinden esinlenilerek oluşturulmuştur. Bu dönemde tek bilgisayarın sağlamayacağı çaptaki işleri gerçekleştirmek için sunucu kümeleri oluşturma olgusu grid bilişim olarak nitelendirilmiştir. Grid bilişimden sonra ise benzer işlevlerine atıfla bulut bilişim kavramı ortaya çıkmıştır. Bulut bilişim ile ilgili genel kabul görmüş bir tanımlama olmamakla beraber, bulut bilişimin bazı yönleri ile grid bilişim olarak adlandırılabileceği görülmektedir. Halen bulut ve grid bilişimin farkları tartışılmaktadır (Weinhardt vd., 2009: 392). NIST (National Institute of Standards and Technology: Amerikan Standartları Enstitüsü) tanımına göre bulut bilişim beş temel karakteristik özelliğe sahip olmalıdır (Mell ve Grance, 2011: 6):

- Talebe dayal, kişisel servis: Bulut bilişim müşterisi, sunucu kaynaklarının kullanımında tek taraflı bir üstünlüğe sahip olmalı, bulut servis sağlayıcısında operasyonel olarak herhangi bir insan kaynağına ihtiyaç duyulmamalıdır.

- Geniş ağ erişimi: Bulut servisleri, mobil telefonlar, tabletler, iş istasyonları ve diz üstü bilgisayarlar gibi her türlü platformdan erişime ve kullanıma açık olmalıdır.

- Kaynakların ortak kullanımı: Bulut bilişim servis sağlayıcısının tüm kaynakları âdem-i tahsis mantığı içerisinde birden fazla müşteri arasında fiziksel sunucuların lokasyonundan bağımsız olarak paylaştırılır. Bu kaynaklar, disk kapasitesi, işlemci hafızası ve ağ bant genişliği olabilir.

- Hızlı Esneklik: Bulut bilişimde sağlanan servisin kapasitesi herhangi bir zamanda ek işleme gerek duyulmaksızın otomatik olarak artabilir.

- Kullan-öde mantığg: Kapasite artışları için geleneksel sistemlerdeki ek işlemlere gerek yoktur. Kullanıcılar bir nevi kullandığı kadar öder.

- Ölçülebilen servisler: Kullanıcının harcadığı işlemci gücü, bant genişliği, kullanıcı hesapları, disk alanı gibi tüm kaynaklar her iki taraf tarafından izlenebilmektedir.

Bulut bilişim kavramının tanımları yazında birbirine benzemektedir. Ancak her tanım bulut bilişimi farklı açılardan betimlemektedir. Örneğin bir tanımda bulut kavramı ve yazılım ve donanımdan müteşekkil olan veri merkezi (data center) olarak tanımlanarak (Armbrust vd., 2010:51) bulut bilişimin mekânsal özelliğine vurgu yapılmaktadır. Bu merkez eğer organizasyon bünyesinde ise "özel bulut", eğer birden fazla farklı organizasyona hizmet vermekte ve ödeme ile direkt olarak sisteme dâhil olmakta ise "dış bulut" olarak nitelendirilmektedir. Dış bulut hizmeti sayesinde farklı firmalar tarafından bilişim altyapısından faydalanma hizmetinin satın alınma imkânı ortaya çıkmaktadır. İç ve dış bulut kavramları bulut kavramının niteliğini değiştirmemektedir. Bununla birlikte, işletmenin kendi içindeki bulutun işletmenin mevcut sunucu altyapısından farkı net değildir. Ancak dış bulut tanımına giren bulut hizmetinin işletmenin kendi altyapısından farklı olduğu açıktır.

Bulut bilişimle ilgili olarak hizmet sağlayanlar ve kullanıcıların perspektifinden birçok araştırma yapılmasına rağmen halen bazı alanlar net değildir ve bulut bilişimde ilerlemenin sağlanması için bu alanların netleştirilmesi gerekmektedir (Marston vd., 2009:178). Bulut bilişim tanımında geçen bir diğer önemli vurgu da bulut bilişimin donanımsal kaynakları servis olarak internet üzerinden sağlamasıdır (Armbrust vd., 2010: 50). Bu durum işletmelerin kendi altyapılarına internetten bağımsız olarak erişmeleri şeklinde olan geleneksel sistemlerin yaklaşımına göre en temel farklardan biridir.

Geleneksel servislerde kurumların kullanıcılarına ve yazılım geliştiricilerine sundukları donanımlara erişim Windows veya Linux ağları üzerinden olmakta ve bu hizmete internet olmasa 
da erişim mümkün olmaktadır. Bulut bilişim uygulamalarında ise donanımlara erişmek için internet gereklidir. Söz gelimi yerel bir sunucu üzerinde bulunan bir veri tabanından yapılacak bir sorgu işlemi için sunucuya bağlanıp oradan bu işlemi yapılmaktadır ve bunun için internet bağlantısına ihtiyaç bulunmamaktadır.

Ancak aynı sorgu işlemini internet adresi olan bir web sayfasından yapmak da mümkündür. Bu duruma Google'ın sunduğu Colab veya Microsoft Azure'un sunduğu çevrimiçi 'Jupyter' ya da Apache Zeppelin not defterleri örnek gösterilebilir. Bu web uygulamasına yüklenen herhangi bir veri direkt olarak Microsoft'un sunucuları üzerinden sorgulanabilmekte ve analiz edilebilmektedir. Bunun için Microsoft sunucularına geleneksel yöntemlerle bağlanmaya ihtiyaç bulunmamaktadır. Bu örnekte belirtildiği şekilde sunuculara erişimin şekli, kullanılan teknolojinin tanımını da değiştirmektedir. Ancak tek farklılık tanım değildir. Bulut ve bulut olmayan teknolojinin birbirlerine göre üstünlükleri ve zayıf yönleri mevcuttur.

Ancak henüz tanımından itibaren başlayan farklı yaklaşımlar bu iki teknolojiyi kıyaslamayı zor hale getirmektedir. Söz gelimi, barındırma hizmeti bakımından bir web uygulamasının geliştiricisi bulut tabanlı hizmet ile geleneksel barındırma hizmeti arasında işlevsel bir fark görmeyebilir. Her ikisi de kodlanmış olan bir uygulamayı kullanıcılarla buluşturmaktadır. Ancak bu süreçte geliştirici, bulut hizmetinde kendine ayrılan sanal alanda uygulamayı geliştirdiği için bulut olmayan teknolojilere göre tam tam bağımsız bir sistemden ziyade belirli bir altyapı (Google, Amazon vs.) içerisinde sunulan otonom bir alanda var olan "Servis olarak platform" (Platform as Service: PaaS) kategorisinde hizmet almaktadır.

\section{Bulut Bilişim ve Organizasyonlar}

Bulut bilişimin yaygınlaşması öncesinde, veri barındırma, veri işleme, veri paylaşımı, web sayfaları ve uygulamaları yayınlama gibi temel bilişimsel işlevler ya işletmelerin kendi sunucularında ya da başka firmalardan hizmet almak suretiyle gerçekleştirilmekteydi. Geleneksel olarak tanımlanan bu yaklaşım halen yaygın bir biçimde kullanılmaktadır. Bulut bilişimin sunduğu bir takım imkânlar geleneksel alternatiflere göre daha fazla kolaylık sağlamasına rağmen, yukarıda anılan kavramsal farklılıklar kullanıcıları bulut bilişim alternatifini geleneksel alternatiflere göre henüz kararlı olmayan bir seçenek olarak düşünmeye sevk edebilmektedir. Örneğin Kalkınma Bakanlığı tarafından kamu kurumlarının bilgi işlem bölümlerinde yaptırılan çalışmaya göre bulut bilişimle ilgili çekinceler halen devam etmektedir (Özdaş, 2014). Bulut bilişimle ilgili yazında bilinen ve bulut bilişimde bilginin güvenliği ve mülkiyeti gibi konulardaki tartışmaların yarattığı ön yargı, verisi bakımından kritik olmayan kurum ve kuruluşları bile bulut bilişimden uzaklaştırabilmektedir.

Bir organizasyon için söz gelimi herhangi bir web uygulamasının yazılım geliştirici tarafından tasarlanarak şirket içinde test edilmek üzere erişime açılması sürecin bitmek üzere olması demek anlamına gelebilir. Ancak yazılım geliştiriciler açısından bakıldığında bu durum sürecin henüz başı olmaktadır. Nitekim web uygulaması sunucuya "gerçek ortam" ya da "product" ortamı olarak adlandırılan ortama taşındığında (deployment) yeni ortamın yazılan kodlara uyumu, performansı, sürekliliği ve de arızi şekilde ortaya çıkabilen trafiğe karşı durumu gibi birçok soru işareti varlığını korumaktadır. Ayrıca sunulan ortamdaki verinin kolayca izlenebilmesi, kesintiye uğramaksızın bu verilerden istifade edilebilmesi, uygulamanın eski versiyonlarının her ihtimale karşı hazır tutulması gibi başka teknik hususlar da mevcut olmaya devam edebilmektedir. $\mathrm{Bu}$ teknik sorunlar organizasyonda yönetim düzeyine çıkmadıkça farkına varılmamakta ve sorun çıkmadan önlem alınması mümkün olmayabilmektedir. Medyada da sıkça görülen hizmet veremediği için askıya alınan web uygulamaları bu durumun önemli örneklerindendir. Performans yanında sunucu altyapısının güvenliği de bir diğer kritik konudur. Sunucuların web uygulamasının sorunsuzca yayınlanması ve güvenliği ise büyük ölçüde yazılım geliştiricilerin uzmanlık alanına girmemektedir. Buna göre bir web uygulaması için istihdam edilecek personel sadece yazılım geliştiricilerden ibaret olmayacaktır. Uygulamalar, bu uygulamalarda yapılan işlemler ve kullanıcı hacmi büyüdükçe ağ ile ilgili departmanlara ihtiyaç artacaktır. Bu ise yeni 
girişimler için ek maliyet kalemi olmaktadır. Tüm bunlar bulut bilişimin alternatifi olan işletme bünyesinde sunucu altyapısı kurmanın maliyetleridir. Bulut bilişim işte bu noktada bir servis olarak maliyet avantajı sağlamakta, özel bir altyapı kurulumu ve sürdürülmesine ihtiyaç birakmamaktadir.

Bazı yazarlar çalışmalarında bulut servislerin ücret ve tip bakımından kapsamlı bir karşılaştırmasını yapmışlardır (Weinhardt vd., 2009:392). Bu tür mukayeseler işletmelerin bulut bilişim ile geleneksel alternatifleri arasında karar vermeleri söz konusu olduğunda değerli bir kaynak oluşturmaktadır. Bu çalışmalarda bahse konu servislerin her biri 'bulut bilişim' kategorisine girmektedir. Ancak her bir servisin sunduğu hizmetlerin kapsamının farklı olması nedeniyle herhangi bir servisi tek başına bulut bilişim platformu olarak görmek doğru olmayacaktır. Amazon ve Google gibi firmalar bulut bilişimle ilgili hemen hemen tüm hizmetleri sunmakta iken, box.net sadece depolama, MuxCloud gibi firmalar ise veri işleme bulut hizmeti sunmaktadir.

Sunduğu hizmetten bağımsız olarak, bulut bilişim ile alternatifi olan barındırma hizmetlerine olan ilgiyi Google Trends hizmetinden de izlemek mümkündür. Bilindiği üzere Google Trends hizmeti Google'da arama yapan herkesin anahtar terimlere yönelik ilgilerinin izlenebildiği bir hizmettir. Buna göre 2004 ila 2007 yılları arasında azalan bir eğilim içinde olmakla birlikte barındırma kavramına (yazılımsal anlamda) ilgi varken, bulut bilişim kavramı ise 2010 yılından itibaren sıkça aranmaya başlamıştır. 2015 yılından bu yana da bulut bilişim kavramı her zaman barındırma kavramından daha fazla aranmıştır (Şekil 1).

Şekil 1. Bulut bilişim ve barındırma kavramına yönelik ilgi (Sarı çizgi bulut bilişimi, mavi çizgi ise barındırma hizmetini temsil eder)

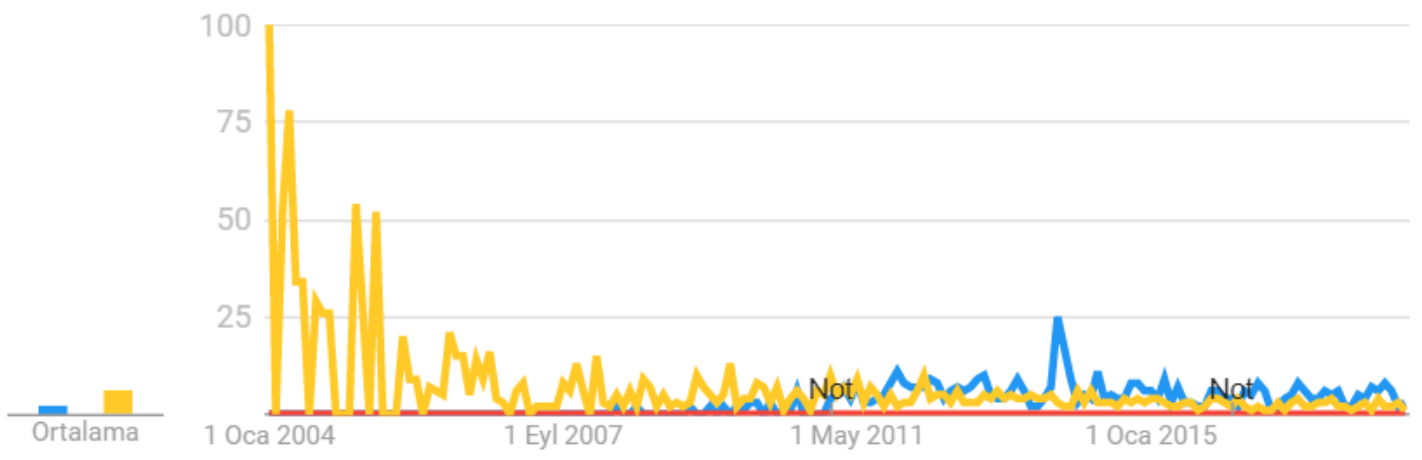

İşletmelere ait web üzerinden sunulmakta olan hizmetlerin barındırıldığı sunucular ilgili hizmete yönelik ilgiye bağlı olarak değişkenlik gösterecektir. Bazı web sayfaları aşırı derecede trafik alırken diğer bazıları çok az trafikle karşılaşabilir. Ancak bu trafik durumu genellikle her an aynı olmamaktadır. Sınav sonuçları ilanları gibi durumlara web sayfası normal aldığı trafiğe göre aşırı derecede yüksek düzeyde bir anlık trafiğe maruz kalmaktadır. Maruz kalınacak trafiğe göre edinilecek sunucuya karar verilirken bu tür durumların göz ardı edilmesi olasıdır.

İnternet ve intranet uygulamalarının popülerleşmesi ile ani taleplere cevap vermeyen geleneksel sunucular artık haberlere konu olmaya başlamıştır ${ }^{2}$. Oysa büyük sosyal medya servisleri ya da popüler web uygulamaları için böyle bir durum haberlere konu olmayacak düzeyde az rastlanır bir durumdur. Trafik düzensizliği durumu örnekle ifade edilecek olursa: Her gün sadece bin civarında ziyaretçi alan bir sunucunun, özel bir nedenle belirli bir günde aldığı ya da alması beklenen ziyaretçi sayısının bir milyon olduğunu varsayalım. Bu durumda sadece ortalama değerlere bakarak karar verildiğinde gerçekçi olunmayacaktır. Eğer bir milyon

${ }^{2}$ http://www.hurriyet.com.tr/gundem/e-devletin-soy-agaci-sorgulama-hizmetine-vatandastan-buyuk-ilgi-sistem-kilitlendi-40735437 
kullanıcıyı kaldırabilecek kapasitede alt yapı yatırımı yapılacaksa ve bu bir milyon ziyaretçinin ticari olarak yarattığı bir değer yoksa yapılan yatırım boşa gitmiş olacaktır. Diğer taraftan eğer bu bir milyon ziyaretçi tümden görmezden gelinip bin civarındaki ziyaretçiyi ancak karşılayan bir altyapı kurulursa bu kez bir milyon ziyaretçi sayfaya yüklendiğinde ilgili organizasyon için itibar kaybı ya da yeni firsatların geri çevrilmesi söz konusu olacaktır. Bu durumda sunucu altyapısı kurmak/kiralamak, gerekli maliyetlerle karşılandığı takdirde geleneksel çözümlerden biridir. Sunucu altyapısı kurmak maliyetlerin sadece görünen tarafıdır. Alınan sunucu sayısı arttıkça bu web uygulamalarının trafiğinin dağıtımı, sunucuların bakımı, güvenliği, güncellenmesi gibi birçok ek masraf da söz konusu olmaktadır.

"Sunucu altyapısı kurmak" şeklindeki geleneksel çözüme alternatif olabilecek en iyi çözüm iç veya dış "bulut bilişim" olmaktadır. Bulut bilişimin en çok işe yarayacağı yerlerden biri de düzenli olmayan trafik akışları karşısında sağladığı verimliliktir.

\section{Kullanıcı İşletmeler Açısından Bulut Bilişimin Olumlu Yönleri}

Bulut bilişimin olumlu ve olumsuz yönleri onu kullanan ve sunan işletmelerin durumlarına göre değişiklik gösterebilir. İşletmelerin faaliyet alanları, yasal statüleri, kaynakları ve diğer özellikleri bu işletmelerin bulut bilişim ile ilgili olanaklardan yararlanması noktasında belirleyicidir. Buna göre bulut bilişimin genel olarak kabul gören olumlu yanları aşağıdaki gibi sıralanmıştır:

İş yerinden bağımsız çalışma avantajı: Çoğu kez bilişim altyapısının fiziksel olarak işletmenin çalışma alanlarında yer alması nedeniyle uzaktan erişimle bu hizmetlere sınırlı olarak erişim dışında iş yeri dışından çalışma olanakları sınırlı olabilmektedir. Yine yazılımların kurulu olduğu bilgisayarların güncellemeleri ve yazılımlar üzerindeki ek modüller de fiziksel konuma bağımlıdır. Örneğin muhasebe yazılımlarından bulut bilişim kullanımı, kullanıcı organizasyonu kurulum ve güncelleme işlemlerinden kurtarması, iş yerinden bağımsız olarak çalışma avantajı sağlaması gibi (Elitaş ve Özdemir, 2014: 103) pratik hayatta önemli hız ve avantaj sağlayan faydalara sahiptir.

Mülkiyet gereksinimini ortadan kaldırma: Bulut bilişimi kullanan organizasyon, faydalanacağ sunucu ve benzeri fiziksel donanım için altyapı yatırımlarına bilfiil sahip olmaktan kurtulmaktadır. Bu durum demirbaş giderlerini ortadan kaldırmakta, bakım, işletme ve güvenlik gibi giderleri de minimize etmektedir. Uzun zaman sarfinda sahip olunan bir sunucunun enerji ve bakım masrafı sunucunun kendi maliyetlerini aşabilmektedir. Sunuculara fiziksel olarak malik olmama sunucuların yangın, sel vb. afetlerde tahrip olması veya bu sunuculara fiziksel olarak erişim suretiyle oluşabilecek güvenlik risklerine karşı da önemli bir avantaj sağlamaktadır.

Bilişimle ilgili inovasyonun önündeki engelleri kaldırma: Yalnızca güçlü firmalarda olan ve küçük girişimlerin elde edemeyeceği altyapılara kolayca erişim sağlama (Marston ve diğerleri, 2009:178) bulut bilişimin avantajlarından biridir. Bu sayede işletmeler donanım yatırımı ile mevcut finansal kaynakları ile elde etmesi çok güç olan ileri teknolojilere ücretsiz olarak veya çok uygun fiyatlarla. Bu duruma verilebilecek en iyi örneklerden biri Google bulut platformunca sunulan Google Vision API'dır. Bu API bulut uygulamalarla bütünleşmiş olarak çalışan ve uygulamaların içindeki resimlerde var olan nesneleri, hayvanları, bitkileri, yazıları, renkleri hatta ünlü kişi, yer ve yapıları tanıma gücüne sahiptir ${ }^{3}$. Benzer şekilde Google App Engine altyapısı web uygulamalarında veri tabanından yapılan sorguları önbelleğe almak için kendi içindeki bütünleşik Memcache API'si ile hız için yapılacak optimizasyonları kolaylaştırmaktadır (Atan, 2012).

Değişken kullanım için maliyet avantajl: Yeni kurulan bir organizasyona ait veya hâlihazırdaki bir şirketin web sayfasının veri tabanı sunucusunun ani bir ilgi sonucu aşırı derece yüklenmesi

${ }^{3} \mathrm{https} / / /$ cloud.google.com/vision/?hl=tr 
olasıdır. Bir web sayfası herhangi bir habere konu olmak veya viral olarak yayılmak suretiyle ciddi bir popülarite kazanarak önemli bir trafik alabilir (Armbrust ve diğerleri, 2010, s. 51). Bu durumda alınacak trafik sonucu da sunucuların başta planlanan kapasiteyi aşarak servis dış1 kalmaları veya yavaşlamaları olasıdır. Bu yavaşlamalar ülkelerin e-devlet servislerinde bile görülebilmektedir. Bu durumlarda işletmeler özelinde özellikle birer ürün olarak yeni piyasaya sürülen uygulamalar tüm iyi özelliklerine rağmen kendilerine dönük ilgiyi kaybedeceklerdir. Bulut bilişimin sunduğu esneklik sayesinde bulut bilişim kullanıcısının kabulü ile hazırlanan web sayfası veya uygulama herhangi bir sınır veya yavaşlamaya maruz kalmaksızın çalışmaya devam edebilir.

İşletmelerin donanımsal kaynakları sürekli olarak aynı düzeyde kullanmamaları, yapılacak bilişimsel altyapı yatırımlarının bazen atıl kalmasına bazen de yetersiz kalmasına neden olabilir. Bu nedenle bu durumdaki işletmelerin bilişim altyapısı yatırımlarına bağlı kalmaksızın faaliyetlerini gerçekleştirebilmeleri için bulut bilişim önemli bir avantaj sağlamaktadır. Bu avantaj özellikle yeni girişimler için faydalı olabilir.

İnovatif iş fikrine sahip geliştiriciler donanıma veya servislerin sürdürülmesini sağlamak için insan gücüne daha fazla ihtiyaç duymamaktadırlar (Armbrust vd., 2010:50). Bir anlamda bulut servisleri bizzat onu sağlayan firmaların da iş gücü ve donanım yatırımı ihtiyacını azaltmaktadır. Bulut bilişi̇imdeki esneklik, söz gelimi 1000 adet sunucuyu 1 saat kullanmak için harcanacak ücretle, 1 sunucuyu 1000 saat kullanmak için ödenecek ücreti neredeyse eşitlemektedir (Armbrust vd.,, 2010:52). Bu esnekliğin insan emeği ve standart paketlere dayalı geleneksel barındırma çözümlerinde mümkün olmadığı bilinmektedir.

Şekil 2. Değişken sunucu trafiği durumunda kapasitenin yetmemesi

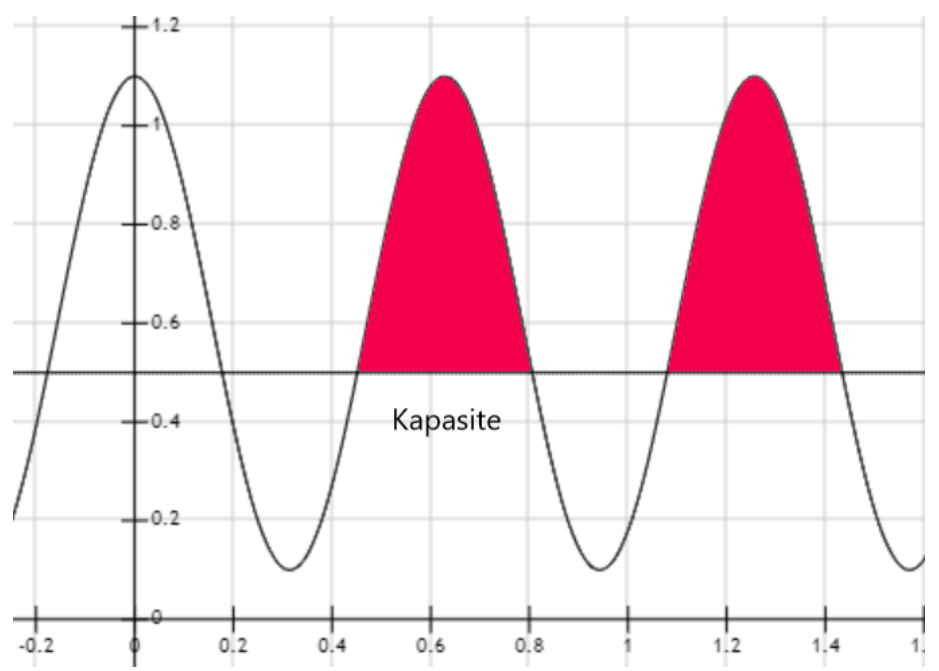

Değişken kapasite kaynaklı olarak yapılan fazlandan altyapı yatırımlarının atıl kalması olgusu ile ilgili olarak şu örnek verilebilir: Şekil 2'de bir farazi bir maaş uygulamasının bulunduğu web sunucusunun varsayımsal trafik yükü gösterilmektedir. Bu sunucu ay ortalarında kullanıcıların bordrolarını kontrol etmeleri ve veri girişi gibi nedenlerden ötürü kapasitesinin üstünde trafiğe maruz kalmaktadır. Bu nedenle işletme ek sunucu tahsis ederek kapasiteyi iki katından daha fazlaya çıkarmıştır. 
Şekil 3. Kapasitenin 2 kattan daha fazla arttırılması durumu

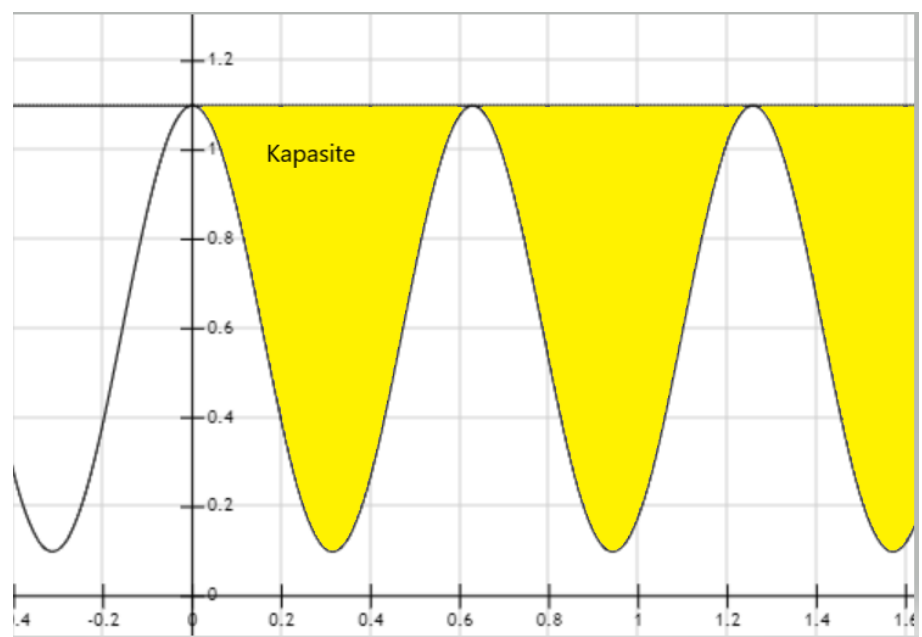

$\mathrm{Bu}$ durumda ise yoğunluğu sunucular kaldırabilmektedir ancak ay ortas1 da dahil tüm trafik eşit dağıldığ 1 takdirde yeterli kapasiteye sahip sunucu altyapısının iki katından fazla bir kapasite çoğunlukla atıl kalmaktadır (Şekil 3). Böyle bir sorun durumunda bulut servisleri dinamik olarak kullanılan kapasiteye göre fiyatlandırma yapma imkânına sahiptir. Bulut bilişim kullanımında her dönemde sunucunun kullanımı kadar ödeme yapılacağından sunucunun aktif olmadığı dönemlerde daha fazla ödeme yapılmasına gerek kalmayacaktır.

İs sürekliliği: Donanım satın alma veya kiralama durumunda sunucuların çökmesi gibi bir durumun gerçekleşme ihtimali her zaman mevcuttur. Bu ihtimale karşı altyapının sürekli olarak hazır halde tutulması amaciyla uzman personel istihdam edilerek sunucuların bakımı ve sürekliliği gerçekleştirilebilir. Ancak bir işletmenin altyapısının devamlılı̆̆ını sağlaması amacıyla personel temin etmesi her zaman mümkün olmayabilir. Küresel çapta bulut hizmeti veren servis sağlayıcıların ise altyapının devamlılığını sağlayacak insan kaynağı altyapısını sürekli olarak bulundurmak durumundadırlar. Bulut bilişim insan kaynağı ihtiyacını da azaltması/yok etmesi bakımından avantaja sahiptir. Bulut bilişim servisleri sağlayıcılarının merkezi olarak çok fazla sayıda bilgisini barındırıyor olması bulut bilişim servis sağlayıcılarının bir takım saldırılara hedef haline gelmesine neden olabilir. Ancak bu noktada da işletmenin kendi bünyesinde kullanılan sunuculardaki yazılımların standart olması ve açıkları keşfedildiğinde standart saldırılara maruz kalabileceği düşünüldüğünde küresel bulut platformu saldırılarının alternatifi olarak geleneksel yöntemleri öne sürmek gerçekçi olmayacaktır. Bulut platformlarının çoğu SLA (Service Layer Agreement) için sürekli aktif olma olma süreleri için garanti vermektedir. Örneğin Amazon AWS \%99.95 çalışma zamanı (uptime) garantisi vermektedir.

Muhasebeleştirme etkinliği: Bulut bilişim, kullanıcıları için sabit giderleri, değişken giderlere dönüştürme özelliğine sahiptir (Armbrust vd., 2010). Bir nevi alınan/verilen bilişim hizmetleri bir demirbaş olmaktan çıkarıp sarf malzemesine dönüştürmektedir. Bu durum demirbaş olarak edinilen sunucu altyapılarının muhasebeleştirilirken kapasitelerinin muhasebe anlamında değerlendirilmesini olanaksız kılmaktadır. Oysa bulut bilişim hizmeti tıpkı elektrik veya su sarfiyatı gibi izlenebilir şekilde faturalandırılabilmektedir.

\section{Büyük Organizasyonlar İçin Bulut Bilişimin Önemi}

Organizasyonların geleneksel yöntemlerle bilişim altyapısı kurmaları söz konusu olduğunda bu organizasyonlarca önlem amaçlı olarak ihtiyaç duyulan kapasiteden fazla kapasitelere yönelik yatırım gerçekleştirileceği tahmin edilebilir. Başka bir deyimle böyle bir durum söz konusu olduğunda her halükarda, bir donanım altyapısı belirli dönemlerde atıl kalmak durumundadır. $\mathrm{Bu}$ durum birden fazla işletmenin teşkil ettiği şirket gruplarında ya da daha büyük 
bir yap1 olarak devletlerin alt organizasyonlarında toplamda ciddi bir kapasitenin atıl kalmasina neden olmaktadır. Kullanılmayan bu kapasiteler toplamda aynı grup içindeki bir başka alt organizasyon için ihtiyaç duyulan kapasiteyi yaratabilecek kadar büyük olabilir (Şekil 4). Bu kapasitelerin boşa harcanması kuşkusuz ekonomik de değildir.

Şekil 4. Sunucu kümelerinde atıl kapasite

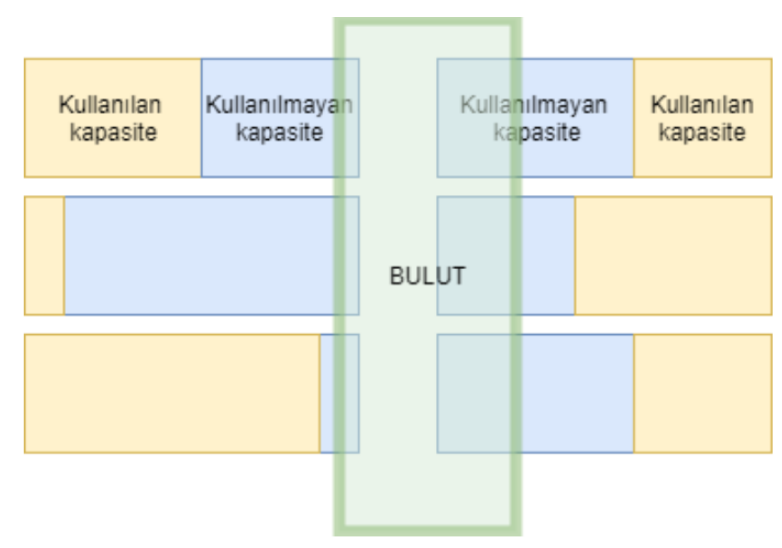

$\mathrm{Bu}$ durumda kullanılmayan kapasiteleri ortak kullanıma açmak için başka bir yol mevcut değilse, donanımsal kaynakları merkezileştirmek üst organizasyonel yapılar için önemli ekonomik avantajlar yaratabilecektir. Aktif olarak kullanılmayan sunucu altyapıları sadece atıl kaldıkları için değil, herhangi bir hizmet vermeseler dahi enerji, insan kaynağı ve her ihtiyaç duyulduğunda bu kapasitelerin arttırılması için yapılan yatırımlar hesaba katıldığında önemli maliyetlere neden olabilecektir.

\section{Kullanıcı İşletmeler Açısından Bulut Bilişimin Olumsuz Yönleri}

Veri transfer güvenliği: Bulut bilişimle ilgili geliştirme süreçlerinde, kafe, restoran, otobüs gibi ortamlarda veri transferinin yapılması ile ilgili riskler bulunmaktadır (Henkoğlu ve Külcü, 2013:68). Bulut bilişim servisleri genellikle kullanıcı adı ve şifre ile erişim sağlanabilen herhangi bir web uygulamasına benzer yapıda olduğundan bu servislere erişim bilgilerinin ortak ağlar üzerinden yetkisiz kişilerin ellerine geçmesi mümkündür. Geleneksel sistemlerde işletmelerin fiziksel mekanları dışında verilerine erişmek kullanıcı adı ve şifreler ele geçirilse bile mümkün olmayabilir. Ancak bulut bilişimde özel bir engel konmadıkça her türlü veri kullanıcı adı ve şifeler mevcutsa her yerden erişilebilir durumdadır.

Veri mülkiyeti: Bulut bilişim servis sağlayıcılarının tutmakta oldukları verilerin mülkiyeti hukuki açıdan ülkeden ülkeye değişiklik göstermektedir (Henkoğlu ve Külcü, 2013, s. 68). Sunucu konumunun (lokasyon) belirsiz olabilmesi (bu her serviste böyle olmamakla birlikte mümkündür) (Marston vd., 2009:179) olumsuz olarak değerlendirilebilir. Özellikle kullanıcılara ait kişisel verileri tutacak uygulamalar için bu durum değerlendirilmelidir.

Adli vakalarda erişim: Bulutta tutulan verilerin yetkililerce gerçekleştirilecek adli inceleme durumunda statüsü ve dijital delil olarak kullanılıp kullanılamayacağına dair belirsizlikler bulunmaktadır (Henkoğlu ve Külcü, 2013:72). Ancak kişilere ait olmayan ve özel olmayan verilerin (açık veriler veya anonim veriler gibi) tutulmasında bir problem olmayacağından özellikle yeni kurulan işletmelerin bu belirsizliği dikkate alarak ek maliyetlere katlanmaları doğru olmayacaktır.

Internet bağlantı hızı problemi: İnternet bağlantısının zayıf olduğu yerlerde, internet üzerinden yüklü miktarda veri transferi yapacak organizasyonlar için bulut bilişim çözümleri kullanımı pratik olmayabilir (Leavitt, 2009:1). 
Bağımlılık riski: İşletmelerin bulut bilişim sağlayıcılarına bağımlı hale gelmesi bir risk olarak görülmektedir (Elitaş ve Özdemir, 2014:101). Nitekim tüm bulut sağlayıcıları kullanıcılara kendi yazılım geliştirme ve yaklaşımlarını teşvik etmektedir. Hemen hemen tüm bulut hizmetler aynı teknolojileri de sağliyor olmakla birlikte (MySQL, MongoDB, Apache) kendi teknolojilerinin kullanılması durumunda ücretsiz hizmetler vererek kullacıları kendi hizmetlerine bağımlı hale getirmeye çalışmaktadırlar. Örneğin Google Compute Engine hizmeti standart MySQL hizmeti gibi bağımlılık yaratmayacak bir aracı ücretli olarak sunarken, kendi özel veri tabanı sistemi olan Datastore teknolojisini ücretsiz olarak sunmaktadır.

Saldırılara hedef olma: Bulut bilişim servis sağlayıcıları daha çok saldırıya maruz kalmaktadır (Elitaş ve Özdemir, 2014:101). Bu saldırılar bulut bilişimin çok fazla sayıda müşterinin verisini barındırmasından kaynaklanmaktadır. Geleneksel sistemler ise sadece bir veya birkaç organizasyona ait verileri barındırdığından olası saldırılar sadece bu organizasyonlara yönelik olacaktır.

\section{Servis Sağlayıcı İşletmeler Açısından Bulut Bilişim}

Bulut bilişimi sunacak işletmeler açısından da olumlu ve olumsuz özellikler farklılık göstermektedir. Bilişim hizmetleri için altyapı kiralayan ya da satan firmaların bulut bilişimle ilgili olarak sahip geleneksel sistemlere göre sahip olacakları avantajlar aşağıda değerlendirilmektedir:

İnsan kaynă̆ına bă̆ımlılı̆̆ın azaltılması: Bulut servis sağlayıcısı firmalar altyapılarını uygun şekilde geliştirdiklerinde servisi kullanacak işletmelerin geleneksel servisleri kullanırken ihtiyaç duydukları telefon görüşmeleri, yazışmalar ve ek başka bürokratik süreçlere ihtiyaçları azaltabilir.

Ek güvenlik maliyetleri: Bulut bilişim firmaları, geleneksel alternatiflere göre bir takım ek maliyetlere katlanmak durumundadır, örneğin barındırdığ 1 verilerin kriptolaması, sistemlerinin erişim güvenliği için ek önlemler gibi işlemler gerekmektedir (Henkoğlu ve Külcü, 2013, s. 67).

Veri koruma sorumluluğu: Bulut servisler sadece web sayfaları değil, işletmenin kullanabileceği birçok veriyi barındırma ve işleme özelliğine sahip olduğundan ayrıca bunu birden fazla firma için gerçekleştirdiğinden bu fonksiyonları ile ilgili hukuki mesuliyeti göz önüne almak durumundadir.

\section{Sonuç ve Değerlendirmeler}

Bulut bilişim ile ilgili olarak yazındaki çalışmaların bulut biliş̧imin tanımı, türleri gibi tanımlayıcı boyutlarını ele alan çalışmalar yanında bulut bilişimin kullanıcıları için sunduğu faydalar ve barındırdığı riskleri ele alan çalışmaların etrafında kümelendiği görülmektedir. Bulut bilişimin faydaları ile ilgili çalışmalarda bulut bilişimin olumlu yönleri ele alınırken hali hazırdaki olumlu örnekler değerlendirilmekte, olumsuz yönler ele alınırken gerçekleşmiş olumsuzluklar veya hali hazırdaki olumsuzlukların değil, muhtemel olumsuzlukların ele alındığı görülmektedir. Bulut bilişim ile ilgili bilinen en büyük olumsuz gelişmeler arasında gösterilen bir olay 2014 yılında gerçekleşmiş olan Apple'a ait iCloud bulut servisinden ünlülere ait fotoğrafların sızdırılması olayıdır ${ }^{4}$. Bu olayda saldırganlar basitçe sık kullanılan şifreleri deneme yanılma yaparak ünlülerin hesabına girmişler üstelik bu deneme yanılmayı yapacak basit Python kodlarını da açık kaynak kod platformu olan GitHub adresinden yayınlanmışlardır. Bu durum bulut bilişim ile ilgili olumsuz bir örnek olarak ele alınmıştır. Oysa bu olayda sorun Apple'ın iCloud'una deneme yanılma ile şifre çalma saldırılarında sunucunun belirli bir sayıdan daha fazla denemeyi robot kontrolü (captcha) yardımıyla engellemesi gerekirken engellememesi ile ilgili problemdir. Öte yandan her halükarda tahmin edilmesi güç şifreler kullanan kişiler bu saldırıdan korunmuştur. Buna göre bu iCloud'a yönelik saldırıdaki olumsuzlukların bir kısmı da kullanıcı hatasından kaynaklanmaktadır. Bu skandaldan sonra yalnızca bulut servisleri değil bir e-posta ve sosyal

\footnotetext{
${ }^{4}$ https://www.forbes.com/sites/davelewis/2014/09/02/icloud-data-breach-hacking-and-nude-celebrity-photos/\#73cff472de72
} 
medya servisi de hali hazırda bankaların da kullandığı SMS ile doğrulama ya da çift katmanlı doğrulama servislerine yönelmiştir.

Kuşkusuz bilişim ile ilgili hiçbir alternatif mutlak güvenlik veya mutlak bilgi güvenliği sağlamayacaktır. Bulut dışındaki geleneksel bilişim alternatifleri de saldırılara maruz kalmaktadır. Yazında karşılaşılan riskler mevcut olmakla birlikte, her işletme için her koşulda geçerli olmayacaktır. Bu noktada sıkça karşılaşılan risklerden bazıları ile ilgili değerlendirmeler aşağıdaki gibidir:

Adli durumlar ve veri mülkiyeti: Yazında verilerin adli durumlarda kullanımı ile ilgili risklerden söz edilmektedir. Ancak özellikle yeni girişimlerin ya da bulutta kritik bilgi saklamayacak işletmeler için bu durum söz konusu değildir. Söz gelimi sadece web sayfasını bulutta tutmak isteyen ve şirket haberlerini buradan yayınlayan bir işletmenin adli incelemeler durumunda bulutta tutulan veri ile ilgili adli veya hukuki kaygılar taşıması yerinde olmayacaktır.

Bulut bilişime yönelik yasal boşluklar kullanıcı adaylarını geleneksel çözümlerle devam etmeye teşvik etmektedir. Bankacılık sektörü de benzer bir süreçten geçmiştir. Bankacılık sektörünün ilk ortaya çıktığı dönemlerde yasal boşluklar bu sisteme dair çekinceler mevcut olagelmiştir (Henkoğlu ve Külcü, 2013). Ancak yasal boşluklar nedeniyle bu ihtiyaçların bir kenara itilmesi söz konusu olmamıştır. İnternet, elektrik, gaz, su artık toplumun talep ettiği bir altyapı hizmeti haline gelmiştir (Buyya vd., 2008:1). İnternetin sunduğu bu imkânlar, internetle beraber ortaya çıkan bir takım başka hizmetlerin de birer servise dönüşmesine neden olmuştur. Bulut bilişimin de bu hizmetlerden olduğu kabul edilebilir nitekim toplumun günlük ihtiyaçlarını karşılarken, işletmelerin kendilerinin sağlayacağı büyük altyapı yatırımlarına ihtiyaç duymamasını sağlar, Nasıl ki işletmeler belirli büyüklüğe ulaşmadan elektriklerini kendileri üretmek yerine farklı firmalardan temin ediyorlarsa, birçok bilişim hizmetini de bulut üzerinden alabilmelidirler. Yazılımsal boyutu bakımından, bulut bilişim ve geleneksel alternatifi olan çözümlerin her ikisi de özünde işletmelerin kendi bünyelerinde geliştirdikleri ya da dişarıdan temin ettikleri yazılımların web veya intranet ortamında kullanıcılara ulaştırma fonksiyonunu üstlenirler. Yazılım projelerinin geliştirilmesi görece uzun zaman dilimlerine yayılmakta ve tamamlandıktan sonra da kullanıma açılması bu iki alternatiften biri üzerinde olmaktadır. Ancak bir yazılım projesinin onu kullanacak ilk kişinin veya test görevlisinin ekranında görülmesi sürecin bittiği anlamına gelmemektedir.

Bağımlılık: Bulut bilişimin kullanıcı işletmeler için bağımlılık yaratması ve daha sonra farklı alternatiflere geçişi zorlaştırması ile ilgili kaygılar herhangi bir bilişim çözümü için de geçerlidir. İşletmeler geleneksel yapıda da zaten her gün altyapılarını değiştirmemektedir. Bilişim sistemleri doğası gereği belirli miktarda yol patika bağımlılığına sahiptir. Söz gelimi günümüzde yaygın olarak kullanılan QWERTY klavyeler en kullanışlı klavye olmadığı halde (Ashwin, 2015) tarihi olarak yaygın kullanımından ötürü diğer alternatiflerine göre daha yaygın kullanılmış ve başarılı olmuştur (Barnes vd., 2004). Bu nedenle bulut bilişimde risk olarak görülen bu konu özünde zaten tüm bilişim sistemlerinde bulunan bir risktir. Bu risk olağan patika bağımlılığı riskinden daha fazla değildir. Aynı şekilde yeni girişimler için henüz emekleme aşamasında olan uygulamaların aşırı derecede veri ve kullanıcı alışkanlıklarına bağlı olarak yol bağımlılığı yaratması olası değildir.

Saldırıya açıklık ve veri transfer güvenliği: Bulut bilişim de dâhil olmak üzere hiçbir bilişim çözümü, barındırma hizmetleri ile tutulan organizasyonlara ait dijital varlıkların yedekleme ve ek tedbirler alınmaksızın korunmasını garanti etmemektedir. Bulut bilişimin daha fazla saldırıya açık olması nedeniyle verilerini yerel sunucularda barındıran bir organizasyonun yerel sunucuların daha da güvenli olduğundan emin olmasını sağlayacak nicel bir ölçüt bulunmamaktadır. Bu nedenle yedekleme ve ek tedbirlerle bulut sunuculardaki verilerin güvenli olarak kabul edilmesinde bir engel yoktur. 
Geleneksel araçlar bulut bilişimle benzer fonksiyonları icra etmektedirler. Örneğin geleneksel bir barındırma çözümü bulut bilişim tarafindan da sunulmaktadır. Bulut bilişimin teknik anlamda kullanıcıları için bir farkının olmaması onları kullanmaya karar veren organizasyon yönetimleri için de farksızlık anlamına gelmemektedir. Nitekim maliyet bakımından ve özellikle de gelecekte büyüme potansiyeli olan ancak şu anda yeterli altyapı ve insan gücüne sahip olmayan işletmeler için sağladığı kolaylık bakımından bulut bilişim özel olarak değerlendirilmesi gereken bir konudur. Bu noktada bulut bilişim kullanmayı planlayan işletmeler için öneriler ortaya konmuştur.

Bulut bilişim ile ilgili şüphelere dayanarak, imkânlarından istifade etmemek yerine organizasyonlar bulut bilişim ile ilgili Bisong ve Rahman (2011:39) tarafından aşağıda ifade edilen hususları gözden geçirerek kendi koşullarına göre daha doğru karar verebilirler. Aşağıdaki hususlar sorgulanarak işletmelerin bulut bilişime geçişi noktasında durumlarını gözden geçirmeleri mümkündür:

- Verinin afet durumunda geri getirme imkânları incelenmelidir.

- Verinin çok uzun yıllar muhafaza edilip edilmeyeceğine dair hususlar incelenmelidir.

- Verinin muhafaza edileceği sunucuların lokasyon ülkesi ve bu durumdaki hukuki koşullar araştırılmalıdır.

- Verinin harici denetim ve adli soruşturulmalara konu olup olmayacağ 1 araştırılmalıdır.

- Bulut servislerinde verinin parçalanması (data segregation) olgusunun olup olmadığı incelenmelidir.

- İşletmeler geleneksel bilişism altyapısı alternatifinin maliyetini gerçekçi bir biçimde ortaya koyarak, bulut bilişime geçiş ile ortaya çıkacak maliyetleri mukayese etmelidir.

- Bulut bilişime geçmeden önce mevcut kapasitenin kullanımı analiz edilmeli, kapasitenin gelecekteki durumu için öngörüler sağlanmalıdır.

\section{Kaynakça}

Armbrust, M., Fox, A., Griffith, R., Joseph, A. D., Katz, R., Konwinski, A., ... Stoica, I. (2010). A view of cloud computing. Communications of the ACM, 53(4), 50-58.

Ashwin. (2015, 24 Haziran). Why The Keys In The Keyboard Are Not Arranged In Alphabetical Order? Science $A B C$. https://www.scienceabc.com/innovation/qwerty-keyboard-over-theyears-why-is-it-the-most-preferred-typing-tool.html adresinden erişildi.

Atan, S. (2012). Google App Engine. KODLAB Yayın Dağıtım.

Barnes, W., Gartland, M. ve Stack, M. (2004). Old Habits Die Hard:Path Dependency and Behavioral Lock-in. Journal of Economic Issues, 38(2), 371-377. doi:10.1080/00213624.2004.11506696

Bisong, A. ve Rahman, M. (2011). An overview of the security concerns in enterprise cloud computing. arXiv preprint arXiv:1101.5613.

Buyya, R., Yeo, C. S. ve Venugopal, S. (2008). Market-oriented cloud computing: Vision, hype, and reality for delivering it services as computing utilities. High Performance Computing and Communications, 2008. HPCC'08. 10th IEEE International Conference on içinde (ss. 5-13). Ieee.

Elitaş, C. ve Özdemir, S. (2014). Bulut bilişim ve muhasebede kullanımı. Muhasebe Bilim Dünyası Dergisi, 16(2).

Fox, B. (2012). Cloud computing a "game-changer" for EU economy, Kroes says. 13 Mart 2018 tarihinde https://euobserver.com/news/117695 adresinden erişildi.

Henkoğlu, T. ve Külcü, Ö. (2013). Bilgi erişim platformu olarak bulut bilişim: Riskler ve hukuksal koşullar üzerine bir inceleme. Bilgi Dünyası, 14(1), 62-86. 
Leavitt, N. (2009). Is cloud computing really ready for prime time? Computer, 42(1).

Marston, S. R., Li, Z., Bandyopadhyay, S., Ghalsasi, A. ve Zhang, J. (2009). Cloud Computing: The Business Perspective. SSRN Electronic Journal. doi:10.2139/ssrn.1413545

Özdaş, M. R. (2014), Bulut Bilişimin Kamuda Kullanımı. Kalkınma Bakanlığı Uzmanlık Tezi

Vithayathil, J. (2017). Will cloud computing make the Information Technology (IT) department obsolete? Information Systems Journal.

Weinhardt, C., Anandasivam, A., Blau, B., Borissov, N., Meinl, T., Michalk, W. ve Stöls ser, J. (2009). Cloud computing-a classification, business models, and research directions. Business \& Information Systems Engineering, 1(5), 391-399.

\section{ETIKK ve BILIMMSEL İLKELER SORUMLULUK BEYANI}

$\mathrm{Bu}$ çalışmanın tüm hazırlanma süreçlerinde etik kurallara ve bilimsel atıf gösterme ilkelerine riayet edildiğini yazar(lar) beyan eder. Aksi bir durumun tespiti halinde Afyon Kocatepe Üniversitesi Sosyal Bilimler Dergisi'nin hiçbir sorumluluğu olmayıp, tüm sorumluluk makale yazarlarına aittir. 